\title{
From Data to Action: Neuroepidemiology Informs Implementation Research for Global Stroke Prevention and Treatment
}

\author{
George A. Mensah ${ }^{a}$ Ralph L. Sacco ${ }^{b}$ Barbara G. Vickrey ${ }^{c}$

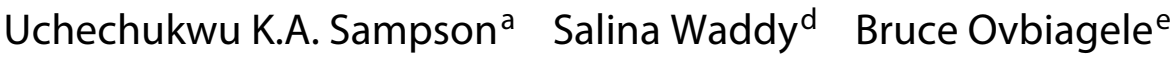 \\ Jeyaraj Durai Pandian ${ }^{f}$ Bo Norrving ${ }^{g}$ Valery L. Feigin ${ }^{h}$ \\ ${ }^{a}$ Center for Translation Research and Implementation Science and Division of Cardiovascular Sciences; National \\ Heart, Lung, and Blood Institute; National Institutes of Health, Bethesda, Md., ${ }^{\circ}$ Departments of Neurology, Public \\ Health Sciences, Human Genomics, and Neurosurgery, Evelyn McKnight Brain Institute, Miller School of Medicine, \\ University of Miami, Miami, Fla., 'Department of Neurology, University of California, Los Angeles, Calif., d'National

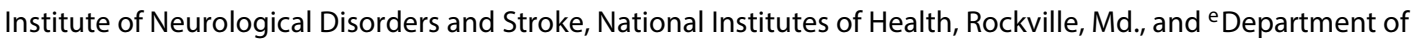 \\ Neurology, Medical University of South Carolina, Charleston, S.C., USA; ${ }^{f}$ Department of Neurology, Christian Medical \\ College, Ludhiana, Punjab, India; ${ }^{9}$ Department of Clinical Sciences, Neurology, Lund University, Lund, Sweden; \\ ${ }^{h}$ National Institute for Stroke and Applied Neurosciences, School of Rehabilitation and Occupation Studies, School \\ of Public Health and Psychosocial Studies, Faculty of Health and Environmental Studies, Auckland University of \\ Technology, Auckland, New Zealand
}

\section{Key Words}

Comparative effectiveness research - Pragmatic trials . Developing country $\cdot$ Health inequities $\cdot$ Implementation research · Neuroepidemiology · Stroke epidemiology · Health policy development

\begin{abstract}
As a scientific field of study, neuroepidemiology encompasses more than just the descriptive study of the frequency, distribution, determinants and outcomes of neurologic diseases in populations. It also includes experimental aspects that span the full spectrum of clinical and population science research. As such, neuroepidemiology has a strong potential to inform implementation research for global stroke prevention and treatment. This review begins with an overview of the progress that has been made in descriptive and experimental neuroepidemiology over the past quarter century with emphasis on standards for evidence generation, critical
\end{abstract}

appraisal of that evidence and impact on clinical and public health practice at the national, regional and global levels. Specific advances made in high-income countries as well as in low- and middle-income countries are presented. Gaps in implementation as well as evidence gaps in stroke research, stroke burden, clinical outcomes and disparities between developed and developing countries are then described. The continuing need for high quality neuroepidemiologic data in low- and middle-income countries is highlighted. Additionally, persisting disparities in stroke burden and care by sex, race, ethnicity, income and socioeconomic status are discussed. The crucial role that national stroke registries have played in neuroepidemiologic research is also addressed. Opportunities presented by new directions in comparative effectiveness and implementation research are discussed as avenues for turning neuroepidemiological insights into action to maximize health impact and to guide further biomedical research on neurological diseases.

() 2015 S. Karger AG, Basel

\section{KARGER 125}

(C) 2015 S. Karger AG, Base

$0251-5350 / 15 / 0453-0221 \$ 39.50 / 0$ 


\section{Introduction}

Neuroepidemiology, a term coined nearly half a century ago, has traditionally been defined as the study of the frequency, distribution, determinants and outcomes of neurologic diseases in human populations. This definition, however, highlights only the non-experimental and descriptive aspects of neuroepidemiology [1]. As a scientific field of study, neuroepidemiology now also includes experimental aspects that span the full spectrum of clinical and population science research encompassing fundamental discovery as well as research into compelling questions and critical challenges around the translation of discovery science findings into health impact in populations with neurological disease [1]. The Global Burden of Disease (GBD) Study findings on stroke reported in this issue of the journal [2-6] and elsewhere [7-11] provide a wealth of data and insights to inform clinical and public health practice as well as to guide health policy development. How do we tap into this wealth of data to inform actions that will maximize health impact?

In this review, we begin with an overview of the progress made in experimental and non-experimental neuroepidemiology over the past quarter century with emphasis on evidence generation, critical appraisal of that evidence and impact on clinical and public health practice at the national, regional and global levels. Attention is then focused on implementation gaps, which include identifying how best to scale-up evidence-based treatments for neurological diseases for various global populations. Evidence gaps in biomedical research, stroke burden, clinical outcomes and disparities between developed and developing countries are described. New directions in comparative effectiveness and implementation research are discussed as avenues for turning neuroepidemiological insights into action to maximize clinical and population health impact and to guide further biomedical research on neurological diseases. The review concludes with a call for rigorous evidence synthesis in neuroepidemiology and the design and execution of novel implementation and dissemination research studies that can lead to practice-based evidence that will underpin a bold new era of data-informed stroke prevention and treatment.

\section{Progress and Challenges in the Last Quarter Century}

Over the last quarter century, neuroepidemiology has matured and is now well-established as a fundamental clinical research approach. There have been significant developments in new statistical methods and study designs that have allowed new evidence generation in nearly all aspects of the distribution, prevention, treatment, rehabilitation and outcomes of neurological disorders. In addition, there has been accumulating knowledge about race/ethnic and sex differences in the distribution and determinants of neurological disorders in various countries and populations. Critical appraisals of that evidence, including systematic reviews and meta-analyses, have led to development of state-of-the art guidelines on the prevention and management of neurological disorders that, in turn, led to changes in policies aimed at reducing the burden of neurological disorders [12]. A recent example is the proposed standards (The STRONG checklist) for reporting incidence and prevalence studies in neuroepidemiology [13].

As another example, in the United States, age-adjusted stroke rates have declined from the third to the fourth leading cause of death $[14,15]$. Stroke prevalence, however, has increased given the increased life span and aging of the population, and stroke remains one of the leading causes of adult disability [14]. In part, decline in stroke mortality was because of decreased incidence, due to improvement in risk factor control, and decreased case fatality, due to the rise of certified stroke centers improving the quality of evidence-based acute stroke care $[16,17]$. Epidemiological research in the United States has resulted in an improved understanding of the public health burden of stroke in high-risk groups, including African Americans and those residing in the southeast United States. Several community-based and multicenter longitudinal epidemiological studies have helped address gaps in our knowledge of stroke epidemiology. Novel stroke risk factors have been identified, and these findings have helped guide interventions that may improve the health of the United States population and others around the globe. These findings may provide new insights into the prevention and treatment of stroke worldwide.

As part of the update to the Stroke Progress Review Group 2012, the Stroke Epidemiology and Risk Factors panel reviewed the state of NIH-funded stroke epidemiology research and summarized advances across several priority areas $[18,19]$. These areas include the following: (1) the development of common data elements (CDE), (2) linkages between epidemiological data and administrative data, (3) stroke trends and (4) research training in epidemiology [18]. For example, data standards that include recommended CDE as well as case report forms, which could be used by epidemiologic studies, have been developed [20-22]. The National Human Genome 
Research Institute has developed the PhenX Toolkit, which provides standard measures related to complex diseases, phenotypic traits and environmental exposures relevant to epidemiological studies of stroke [23-25]. Furthermore, the NIH has also supported other activities including Quality of Life in Neurological Disorders funded by NINDS, the NIH Toolbox for the Assessment of Neurological and Behavioral Function and the PatientReported Outcomes Measurement Information System, which provide standardized validated self-report measures to be incorporated for neurological disorders, freely available to providers and practitioners. Several $\mathrm{NIH}$-funded grants are now linking population-based epidemiologic studies to Medicare data, enabling the identification of stroke without the difficulty and expense of medically verified stroke events [26-29]. Training opportunities in clinical research methodology and epidemiology had been increased through the broad array of NINDS research training and career development programs $[18,19]$.

Similar advances in neuroepidemiology have been made in the high-income countries of Western Europe, Australia, New Zealand and Japan, as well as in low- and middle-income countries [30-32]. In Tanzania, for example, stroke incidence was assessed in 2 surveillance sites: Hai (rural) and Dar-es-Salaam (urban) from 20032006 [32]. Individuals with stroke were systematically identified by community-based investigators and coordination with local medical center personnel. Crude annual stroke incidence rates were 94.5 per 100,000 in Hai and 107.9 per 100,000 in Dar-es-Salaam, but when age-standardized to the WHO world population, annual stroke incidence was 108.6 per 100,000 in Hai and 315.9 per 100,000 in Dar-es-Salaam [32]. To place these data in context, age-standardized stroke incidence rates in Hai were similar to those reported in developed countries, but those in Dar-es-Salaam were higher than figures from high-income countries.

Furthermore, GBD data for the sub-Saharan Africa (SSA) region showed that the amount of increase in the age-standardized ischemic stroke incidence for 19902010 ranged between 5.2\% (South Africa) and 27.8\% (Democratic Republic of Congo), and for hemorrhagic stroke, the increase in incidence ranged between $13.0 \%$ (The Gambia) and 45.7\% (Burundi) [10,33]. Thus, based on the limited available evidence, the incidence of stroke in Africa not only ranks among the highest globally, but its rate of increase is also significant compared to other world regions. Stroke is also the premier cause of cardiovascular disability-adjusted life years (DALYs) in SSA,

From Data to Action in Stroke Prevention and Treatment rising from 5.9 million (39.5\%) in 1990 to 7.8 million $(52.0 \%)$ of cardiovascular DALYs in 2010 [34]. While there is paucity of data on the economic burden of stroke in SSA, a study of the cost of stroke care in Togo noted a direct cost per person of EUR 936 in just 17 days, which is approximately 170 times the average annual health spending of a Togolese [35].

Thus, in SSA, while modest yet important progress has been made in obtaining neuroepidemiologic data relevant for enhancing stroke outcomes overall, more studies are warranted. Ongoing studies like the Stroke Investigative Research and Educational Network (SIREN) Project may yield important new knowledge [36]. SIREN aims to identify the unique risk factors (genetic and environmental) linked to stroke occurrence, subtype, distribution and prognosis in SSA by evaluating 3,000 stroke case-control pairs at 9 sites in West Africa [36]. Furthermore, SIREN will also engage patients, caregivers and local leaders about stroke prevention and treatment, which will help promote better uptake of medical regimen, adherence, behavioral modification and educate and sensitize the community to early presentation of stroke cases at home to allow for greater facilitation to hospitals for treatment [36].

In spite of significant progress, there remain major knowledge gaps in many aspects of stroke epidemiology including elucidation of the determinants of stroke and stroke risk factor disparities by sex, race and ethnicity; impact of unhealthy diets and the rise in physical inactivity, obesity and diabetes; predictors of stroke recovery; and impact of vascular disease on cognitive aging and dementia. Among these, the 3 top priorities for future directions of stroke epidemiology recommended by the Stroke Progress Review Group 2012 included (1) improving the understanding of race and ethnicity in stroke disparities, (2) evaluation of the usefulness of health information technology as a tool for epidemiology research and (3) translating knowledge from epidemiological studies into improved health [18, 19].

Continued support of epidemiologic stroke studies that monitor trends in stroke burden, fill gaps in knowledge and discover new associations should be a high priority. Critically, we need to accelerate the translation of the results from epidemiology studies into improved health by informing evidence-based practice recommendations and clinical care, translating findings into behavioral interventions and providing the fundamental preliminary data needed for randomized clinical trials.

In spite of this progress in the design, methodologies and analyses of stroke epidemiological studies and in 
knowledge gains, a number of unresolved issues and inconsistent findings in stroke prevention and management require further attention. From systematic reviews and GBD data, there are also deepening gaps between developed and developing countries in stroke research and burden $[7,8]$. For example, although the bulk of the global burden of stroke resides in low- and middle-income countries, the majority of research on and evidence for stroke prevention and management comes from developed countries $[9,10]$. Stroke incidence and mortality rates have been declining consistently over the past 4 decades in developed countries, but stroke incidence and mortality rates in developing countries are on the rise [8]. Additionally, in every country examined, the absolute number of people affected, disabled by and/or who die from stroke annually is increasing [7]. While the former is likely due to the lack of evidence for population-specific and culturally appropriate preventive and management strategies in developing countries $[9,10]$, the latter suggests that currently used primary stroke prevention strategies targeting primarily high cardiovascular risk individuals are not effective enough. Thus, new and more effective primary stroke prevention strategies are urgently needed worldwide [11].

\section{Persisting Stroke Disparities}

Health disparities in stroke and stroke care remain pervasive worldwide. Despite major initiatives at the national and sub-national levels to reduce and eliminate these disparities, they have remained remarkably persistent and in some settings have widened [37]. In the United States - where the elimination of health disparities was one of 2 overarching strategic health objectives for 2000 2010 , and substantial declines in age-adjusted mortality rates occurred in both blacks and whites - the magnitude of racial and geographic stroke disparities substantially increased during that period [37]. These disparities have persisted in stroke mortality, morbidity, prevalence of risk factors, healthcare access and in stroke quality of care.

Findings from the Northern Manhattan Study and other epidemiological studies have demonstrated racial and ethnic differences in stroke incidence. Increased annual stroke incidence was 2.4-fold among blacks and 2 -fold among Hispanics compared to whites living in the same community [38, 39]. Blacks in Cincinnati and Mexican Americans in Corpus Christi also have been found to have an increased incidence of stroke compared to whites [40-42]. American Hispanics not only have stroke more frequently, but also have a greater risk of small vessel stroke (lacunar infarcts and intracerebral hemorrhage) and intracranial atherosclerosis [43].

Potential explanations for these race-ethnic disparities include variations in risk factor potency, prevalence and access to treatment arising from socioeconomic, environmental and genetic factors [44, 45]. For example, hypertension is a major contributor to black versus white differences in stroke risk [46], and underlying disparities in the prevalence of ideal cardiovascular health, including modifiable lifestyle behaviors and treatable health factors, are major contributors to differences in the incidence of stroke, myocardial infarction and vascular death [47]. However, traditional risk factors contribute to less than half of the black-to-white racial disparities in stroke. The unexplained additional risk may potentially be attributable to other sources that require further investigation [48]. A recent large and robust case-crossover study in the United States showed that acute infection disproportionately increases the risk of stroke death for non-Hispanic blacks and thus contributes to racial disparity in stroke mortality [49]. Reducing stroke disparities will require innovative approaches to improve cardiovascular health across all race and ethnic groups and specific interventions for addressing disparities.

Studies have documented disparities in access to acute stroke care, activation of 911 services, delayed arrival to the emergency departments, longer waiting times and treatment delays in thrombolysis [50]. Moreover, secondary and tertiary stroke prevention programs are initiated during the acute hospital phase and may also demonstrate care disparities. Decisions made about the use of antiplatelet medications, oral anticoagulants, hypertension control, statin treatment, diagnosis and control of hyperglycemia, the need for lifestyle management and referral for rehabilitation services may demonstrate disparities by race, ethnicity, socioeconomic status or sex.

The Get With the Guidelines (GWTG)-Stroke program was developed by the American Heart Association/ American Stroke Association to improve acute stroke performance by implementing evidence-based care. Over the last few years, it has grown to include data from over 2 million stroke admissions from more than 1,600 United States hospitals. GWTG data have provided important insights into disparities in the quality of stroke care [51]. Moreover, adherence to evidence-based guidelines and quality improvement programs are a very effective way to minimize and eliminate acute stroke disparities. Eliminating stroke disparities will require multilevel interven- 
tions across multi-sectors that address not only individual stroke risk factors, but also the social and environmental conditions that disproportionately expose race-ethnic groups to elevated risk.

\section{Gaps in Implementation Research in Stroke Prevention and Treatment}

The major scientific and technological advances in the detection, evaluation, treatment and control of neurological disorders have not been matched by commensurate advances in factors that drive sustained implementation of evidence-based interventions in different practice settings [52-54]. Research advances have led to the development of tools to detect stroke and determine the underlying cause to inform treatment decision-making. These advances have also been important in stroke drug development and in stroke treatment and prevention protocol development. These strategies have been instrumental in identifying the major challenge areas but have provided limited information on how individual hospitals and practices can adopt protocols and improve the prevention and treatment of stroke in practice.

The first national stroke registry was established in Sweden in 1994, and since then, many other similar registries have been developed. A recent review identified the existence of 28 national stroke registries in 26 countries [55]. The 2 major approaches to monitoring the quality of care with a registry were the following: (1) traditional registries, which provide the most comprehensive data, but are resource-intensive and have optimal coverage when mandatory and (2) administrative database linkage, which is cheaper with greater coverage, but often lacks detail, is more prone to misclassification bias, and is feasible in only some jurisdictions. Almost all national stroke quality registers are located in high- or middle-income countries.

Within the United States, stroke quality improvement initiatives such as the GWTG-Stroke and the Joint Commission Certification levels of stroke certification have sustained and improved inpatient stroke quality measure compliance and in turn improved stroke outcomes and possibly prevention of recurrent stroke in the hospitals that have adopted the program [56]. GWTG not only informs hospital system and healthcare practitioners of the accepted guidelines for stroke care, it also helps to organize stroke care at hospitals and works to identify barriers to optimal care through data collection, analysis, feedback and process improvement. GWTG-Stroke has not

From Data to Action in Stroke Prevention and Treatment been widely adopted outside of the United States. Taiwan and Brazil are the first and second countries with hospitals to adopt the key indicators identified in GWTG and publish initial information on the outcomes $[57,58]$. Adopting GWTG-Stroke requires tailoring regarding the quality indicators that are collectible, how frequently to measure a given indicator and having the opportunity and resources to intervene.

Despite recent progress, there is little information available regarding stroke and actionable targets for improvement in many parts of the world, particularly in low- and middle-income countries. There has also been slow adoption and limited tailoring of quality improvement programs and slow utilization of available tools to advance stroke detection, treatment and prevention. Although these examples of successful implementation of knowledge into practice are excellent, they are the exceptions. For example, despite these advanced state of stroke care in the Taiwan and Brazil studies, there is limited use of further testing that can be useful in correctly identifying the cause of stroke and better treatment. In general, we also lack data on how to turn clinical insights from research discoveries into sustained population health impact $[59,60]$.

\section{Turning Data into Action - An Agenda for Implementation Research}

Over a decade ago, the Institute of Medicine's Clinical Research Roundtable issued a report that showed that one of the 'bottlenecks' in turning data from clinical trials into actions leading to widespread improvements in health was the lack of research on the best way to implement efficacious interventions from such trials in the community and clinical practice settings that reach the population at risk [61]. Typically, these trials are nearly always conducted under conditions tightly controlled by investigators and among narrow, relatively homogeneous patient samples. While this translational bottleneck has analogous obstacles to those that delay translation of basic research into efficacy trials in humans, what is markedly different is the type of scientific disciplinary expertise necessary for translation from those efficacy trials into population health, as well as the type of research infrastructure needed for this research, and the very underdeveloped funding streams for this effort. In the past decade, the field of implementation science has emerged, encompassing multidisciplinary research requiring social science, behavioral science, public health and health services research expertise and methods. At the same time, 
comparative effectiveness has emerged as a new term for an old concept, which is that new advances in diagnosis and treatment should be compared with existing standard approaches, rather than to placebo [62].

Both comparative effectiveness and implementation research have been invigorated in the last decade by new policies and funding streams, a consequence in the United States of the necessity and urgency of restraining healthcare costs that have continued to rise much more rapidly than the country's economic growth. It was the United States Congressional Budget Office that first produced a comprehensive report on the fledgling vision of comparative effectiveness and its potential contribution to rigorous evaluation of alternatives in healthcare [63]. Similarly, the Affordable Care Act led to funding that established the Patient-Centered Outcomes Research Institute and to the Centers for Medicare and Medicaid Services portfolio of funding for scaling up evidence-based healthcare delivery innovations. It also led to development of targets for the proportion of the Medicare population covered under radically different payment policies that incentivize meeting a priori targets for quality of care and reducing unnecessary healthcare utilization ('value-based care') [64]. At the same time, the introduction of these changes holds great promise for addressing racial and ethnic disparities in healthcare, not only by improving access as through expanded coverage under the Affordable Care Act, but also by enabling testing and scaling up of innovative models of care that may be more highly effective in vulnerable populations and which cannot be paid for under prevailing fee-for-service payment structures.

There are well-characterized approaches for development of practice guidelines based on systematic reviews and structured group judgments of the extant literature that national and international stroke associations, other professional societies and the Institute of Medicine have pioneered $[65,66]$. Stroke is one of the most highly prevalent and devastating neurological conditions compared to other neurological disorders; there has been a substantial body of research to develop new treatments, particularly in acute stroke care but increasingly in primary and secondary prevention and in rehabilitation. This makes stroke a condition that is ripe for comparative effectiveness and implementation research, to ensure that the new knowledge generated from these trials of stroke therapeutics and prevention approaches indeed result in the population health benefits that were the ultimate goal of the societal investment in biomedical research on causes and consequences of stroke. An example of a lag in translation of high-quality evidence into practice is multidisciplinary acute stroke units. Although compelling evidence from several randomized trials demonstrate that they reduce mortality, improve outcomes and confer a clear protective effect in those facilities conducting the trials [67], uptake and diffusion of these effective strategies by the stroke teams in acute care hospitals has been very slow. Delays in translation of efficacious treatment approaches into widespread practice mean lost lives and increased morbidity.

Another prime example of the importance of implementation research in stroke is secondary stroke prevention. There is substantial evidence as to what contributes to risk of recurrent stroke and what can prevent recurrent stroke: control of high blood pressure, antithrombotic medication, low-density lipoprotein control, smoking cessation and appropriate diet and levels of physical activity. Yet, hypertension control in the United States remains suboptimal at less than $50 \%[68,69]$, and in several studies, only one-third of individuals known to be at high risk for stroke had achieved control of blood pressure and low-density lipoprotein 1 year after identification as high risk [70]. Those with lower access to healthcare and language and literacy barriers have worse stroke risk factor control and higher recurrent events. In response to this, the NINDS has invested in an initiative to produce evidence for innovative approaches to primary and secondary stroke prevention in vulnerable populations [71].

To leverage the current body of neuroepidemiology research into action that yields demonstrable benefits in population health and reduction or elimination of health disparities, national implementation goals or targets for specific, high-prevalence neurologic conditions such as stroke need to be set, then a roadmap developed for achieving those targets, based on research and researchto-practice gaps in knowledge and by fostering handoffs along the translational spectrum among key stakeholders. The process should engage multiple stakeholders including public and private sponsors of research together with academic, community, delivery system and public health representatives and decision-makers. A mechanism for periodic assessment of progress relative to those goals is essential.

\section{Conclusions}

With new and constantly evolving methods of neuroepidemiological studies, their wider use and increasing implementation across the globe, neuroepidemiology is 
expected to play a central role in the translation of evidence on the frequency, distribution and determinants of neurological disorders to clinical and public health practice in order to maximize individual patient and population health impact $[72,73]$. However, turning descriptive, analytical and experimental neuroepidemiological data into clinical and public health action for population health impact requires quality data, rigorous evidence synthesis and the design and execution of rigorous dissemination and implementation research that incorporate the dynamics and complexities of the healthcare system context in which interventions are delivered $[74,75]$. There is an urgent need for research that can lead to evidence-based recommendations for practice. Important among these are comparative effectiveness studies and large, simple, pragmatic trials that will generate practicebased evidence. Concerted, coherent and timely translation of the knowledge generated into evidence-based recommendations for practice with corresponding changes in health policy at the governmental levels will be crucial. Meaningful changes in practice will require early and sustained engagement of multiple, diverse stakeholders including public and private sponsors of research together with academic, community, delivery system and public health representatives and decision-makers in order to reduce the burden of stroke worldwide.

\section{Acknowledgments}

The authors thank Drs. B.G. Vickrey, Michael Engelgau, Emmanuel Peprah, Helena Mishoe and Andrew Moran who provided critical review and constructive input on an earlier version of this document.

\section{Disclosure Statement}

The authors have no conflicts of interest.

\section{Disclaimer}

The views expressed in this article are those of the authors and do not necessarily represent the views of the National Heart, Lung, and Blood Institute; National Institute of Neurological Disorders and Stroke; National Institutes of Health or the United States Department of Health and Human Services.

\section{References}

1 Feigin V, Kurtzke JF, Korczyn A, Beghi E, Brown A: Bridging the gap between experimental and non-experimental neuroepidemiology, and ultimately - between neuroepidemiological research and practice: round table discussion at the First International Congress on Clinical Neurology and Epidemiology. Neuroepidemiology 2009;33:296-304.

2 Feigin VL, Krishnamurthi RV, Parmar P, Norrving B, Mensah GA, et al: Update on the global burden of ischemic and hemorrhagic stroke in 1990-2013: the GBD 2013 study. Neuroepidemiology 2015;45:161-176.

3 Krishnamurthi RV, deVeber G, Feigin VL, et al: Stroke prevalence, mortality and disabilityadjusted life years in children and youth aged $0-19$ years: data from the global and regional burden of stroke 2013. Neuroepidemiology 2015;45:177-189.

4 Krishnamurthi R, Moran AE, Feigin VL, et al: Stroke prevalence, mortality and disabilityadjusted life years in young adults aged 20-64 years: data from the global and regional burden of stroke 2013. Neuroepidemiology 2015; 45:190-202.

5 Barker-Collo S, Bennett DA, Krishnamurthi $\mathrm{RV}$, et al: Sex differences in stroke incidence, prevalence, mortality and disability-adjusted life years: results from the global burden of disease study 2013. Neuroepidemiology 2015; 45:203-214.
6 Feigin VL, Mensah GA, Norrving B, Murray CJL, Roth GA, et al: Atlas of the global burden of stroke (1990-2013): the GBD 2013 study. Neuroepidemiology 2015;45:230-236.

7 GBD 2013 Mortality and Causes of Death Collaborators: Global, regional, and national age-sex specific all-cause and cause-specific mortality for 240 causes of death, 1990-2013: a systematic analysis for the Global Burden of Disease Study 2013. Lancet 2015;385:117171.

8 Global Burden of Disease Study 2013 Collaborators: Global, regional, and national incidence, prevalence, and years lived with disability for 301 acute and chronic diseases and injuries in 188 countries, 1990-2013: a systematic analysis for the Global Burden of Disease Study 2013. Lancet 2015;386:743800.

9 Bennett DA, Krishnamurthi RV, Barker-Collo S, Forouzanfar $\mathrm{MH}$, Naghavi M, Connor M, Lawes CM, Moran AE, Anderson LM, Roth GA, Mensah GA, Ezzati M, Murray CJ, Feigin VL: The Global Burden of Ischemic Stroke: findings of the GBD 2010 study. Glob Heart 2014;9:107-112.

10 Feigin VL, Forouzanfar MH, Krishnamurthi R, Mensah GA, Connor M, Bennett DA, Moran AE, Sacco RL, Anderson L, Truelsen T, O’Donnell M, Venketasubramanian N, Barker-Collo S, Lawes CM, Wang W, Shinohara Y,
Witt E, Ezzati M, Naghavi M, Murray C: Global and regional burden of stroke during 1990-2010: findings from the Global Burden of Disease Study 2010. Lancet 2014;383:245254.

11 Krishnamurthi RV, Moran AE, Forouzanfar $\mathrm{MH}$, Bennett DA, Mensah GA, Lawes CM, Barker-Collo S, Connor M, Roth GA, Sacco R, Ezzati M, Naghavi M, Murray CJ, Feigin VL: The Global Burden of Hemorrhagic Stroke: a summary of findings from the GBD 2010 study. Glob Heart 2014;9:101-106.

12 Bennett DA, Brayne C, Feigin V: A commentary on the standards of reporting of neurological disorders checklist: a guideline for the reporting of descriptive studies in neuroepidemiology. Neuroepidemiology 2015;45:7172.

13 Bennett DA, Brayne C, Feigin VL, BarkerCollo S, Brainin M, Davis D, Gallo V, Jetté N, Karch A, Kurtzke JF, Lavados PM, Logroscino G, Nagel G, Preux PM, Rothwell PM, Svenson LW: Development of the standards of reporting of neurological disorders (STROND) checklist: a guideline for the reporting of incidence and prevalence studies in neuroepidemiology. Eur J Epidemiol 2015;30:569-576.

14 US Burden of Disease Collaborators: The state of US health, 1990-2010: burden of diseases, injuries, and risk factors. JAMA 2013; 310:591-608 
15 Centers for Disease Control and Prevention, National Center for Health Statistics: Deaths: Final Data for 2013. CDC/NCHS.

16 Lackland DT, Roccella EJ, Deutsch AF, Fornage M, George MG, Howard G, Kissela BM, Kittner SJ, Lichtman JH, Lisabeth LD, Schwamm LH, Smith EE, Towfighi A: Factors influencing the decline in stroke mortality: a statement from the American Heart Association/American Stroke Association. Stroke 2014;45:315-353.

17 Towfighi A, Saver JL: Stroke declines from third to fourth leading cause of death in the United States: historical perspective and challenges ahead. Stroke 2011;42:2351-2355.

18 Sacco R, Lisabeth L, Kissela B, Fullerton H, Gorelick P, Howard G, Kittner S, Lichtman J, Reeves M, Wolf P, Woo D, Moy C, Waddy S: Epidemiology and Risk Factors: Final Report of the Stroke Progress Review Group. National Institutes of Neurological Diseases and Stroke, NIH.

19 Moskowitz MA, Grotta JC, Koroshetz WJ: The NINDS Stroke Progress Review Group final analysis and recommendations. Stroke 2013;44:2343-2350.

20 Biering-Sørensen F, Charlifue S, Devivo MJ, Grinnon ST, Kleitman N, Lu Y, Odenkirchen $\mathrm{J}$ : Incorporation of the international spinal cord injury data set elements into the National Institute of Neurological Disorders and Stroke Common Data Elements. Spinal Cord 2011;49:60-64.

21 Loring DW, Lowenstein DH, Barbaro NM, Fureman BE, Odenkirchen J, Jacobs MP, Austin JK, Dlugos DJ, French JA, Gaillard WD, Hermann BP, Hesdorffer DC, Roper SN, Van Cott AC, Grinnon S, Stout A: Common data elements in epilepsy research: development and implementation of the NINDS epilepsy CDE project. Epilepsia 2011;52:1186-1191.

22 Saver JL, Warach S, Janis S, Odenkirchen J, Becker K, Benavente O, Broderick J, Dromerick AW, Duncan P, Elkind MS, Johnston K, Kidwell CS, Meschia JF, Schwamm L: Standardizing the structure of stroke clinical and epidemiologic research data: the National Institute of Neurological Disorders and Stroke (NINDS) Stroke Common Data Element (CDE) project. Stroke 2012;43:967-973.

23 McCarty CA, Berg R, Rottscheit CM, Waudby CJ, Kitchner T, Brilliant M, Ritchie MD: Validation of PhenX measures in the personalized medicine research project for use in gene/environment studies. BMC Med Genomics 2014;7:3.

24 Stover PJ, Harlan WR, Hammond JA, Hendershot T, Hamilton CM: PhenX: a toolkit for interdisciplinary genetics research. Curr Opin Lipidol 2010;21:136-140.

25 Hendershot T, Pan H, Haines J, Harlan WR, Junkins HA, Ramos EM, Hamilton CM: Using the PhenX toolkit to add standard measures to a study. Curr Protoc Hum Genet 2011; Chapter 1:Unit1.21.

26 Henderson KM, Clark CJ, Lewis TT, Aggarwal NT, Beck T, Guo H, Lunos S, Brearley A,
Mendes de Leon CF, Evans DA, Everson-Rose SA: Psychosocial distress and stroke risk in older adults. Stroke 2013;44:367-372.

27 Levine DA, Davydow DS, Hough CL, Langa KM, Rogers MA, Iwashyna TJ: Functional disability and cognitive impairment after hospitalization for myocardial infarction and stroke. Circ Cardiovasc Qual Outcomes 2014; 7:863-871.

28 Reeves MJ, Fonarow GC, Smith EE, Pan W, Olson D, Hernandez AF, Peterson ED, Schwamm LH: Representativeness of the get with the guidelines-stroke registry: comparison of patient and hospital characteristics among Medicare beneficiaries hospitalized with ischemic stroke. Stroke 2012;43:44-49.

29 Fonarow GC, Smith EE, Reeves MJ, Pan W, Olson D, Hernandez AF, Peterson ED, Schwamm LH: Hospital-level variation in mortality and rehospitalization for medicare beneficiaries with acute ischemic stroke. Stroke 2011;42:159-166.

30 Feigin VL, Forouzanfar MH, Krishnamurthi R, Mensah GA, Connor M, Bennett DA, Moran AE, Sacco RL, Anderson L, Truelsen T, O'Donnell M, Venketasubramanian N, Barker-Collo S, Lawes CM, Wang W, Shinohara Y, Witt E, Ezzati M, Naghavi M, Murray C: Global and regional burden of stroke during 1990-2010: findings from the Global Burden of Disease Study 2010. Lancet 2014;383:245254.

31 Owolabi MO, Akarolo-Anthony S, Akinyemi $\mathrm{R}$, Arnett D, Gebregziabher M, Jenkins C, Tiwari $\mathrm{H}$, Arulogun O, Akpalu A, Sarfo FS, Obiako R, Owolabi L, Sagoe K, Melikam S, Adeoye AM, Lackland D, Ovbiagele B: The burden of stroke in Africa: a glance at the present and a glimpse into the future. Cardiovasc J Afr 2015;26(2 suppl 1):S27-S38.

32 Walker R, Whiting D, Unwin N, Mugusi F, Swai M, Aris E, Jusabani A, Kabadi G, Gray WK, Lewanga M, Alberti G: Stroke incidence in rural and urban Tanzania: a prospective, community-based study. Lancet Neurol 2010; 9:786-792.

33 Krishnamurthi RV, Feigin VL, Forouzanfar $\mathrm{MH}$, Mensah GA, Connor M, Bennett DA, Moran AE, Sacco RL, Anderson LM, Truelsen $\mathrm{T}$, O'Donnell M, Venketasubramanian N, Barker-Collo S, Lawes CM, Wang W, Shinohara Y, Witt E, Ezzati M, Naghavi M, Murray C: Global and regional burden of first-ever ischaemic and haemorrhagic stroke during 1990-2010: findings from the Global Burden of Disease Study 2010. Lancet Glob Health 2013;1:e259-e281.

34 Moran A, Forouzanfar M, Sampson U, Chugh S, Feigin V, Mensah G: The epidemiology of cardiovascular diseases in sub-Saharan Africa: the Global Burden of Diseases, Injuries and Risk Factors 2010 Study. Prog Cardiovasc Dis 2013;56:234-239.

35 Guinhouya KM, Tall A, Kombate D, Kumako V, Apetse K, Belo M, Balogou AK, Grunitzky KE: [Cost of stroke in Lomé (Togo)]. Sante 2010, Epub ahead of print.
36 Akpalu A, Sarfo FS, Ovbiagele B, Akinyemi R, Gebregziabher M, Obiako R, Owolabi L, Sagoe K, Jenkins C, Arulogun O, Adamu S, Appiah LT, Adadey MA, Agyekum F, Quansah JA, Mensah YB, Adeoye AM, Singh A, Tosin AO, Ohifemen O, Sani AA, Tabi-Ajayi E, Phillip IO, Isah SY, Tabari NA, Mande A, Agunloye AM, Ogbole GI, Akinyemi JO, Akpa OM, Laryea R, Melikam SE, Adinku D, Uvere E, Burkett NS, Adekunle GF, Kehinde SI, Azuh PC, Dambatta AH, Ishaq NA, Arnett D, Tiwari HK, Lackland D, Owolabi M: Phenotyping stroke in sub-Saharan Africa: stroke investigative research and education network (SIREN) phenomics protocol. Neuroepidemiology 2015;45:73-82.

37 Howard G: Ancel keys lecture: adventures (and misadventures) in understanding (and reducing) disparities in stroke mortality. Stroke 2013;44:3254-3259.

38 White H, Boden-Albala B, Wang C, Elkind MS, Rundek T, Wright CB, Sacco RL: Ischemic stroke subtype incidence among whites, blacks, and Hispanics: the northern Manhattan study. Circulation 2005;111:1327-1331.

39 Sacco RL, Boden-Albala B, Gan R, Chen X, Kargman DE, Shea S, Paik MC, Hauser WA: Stroke incidence among white, black, and Hispanic residents of an urban community: the northern Manhattan stroke study. Am J Epidemiol 1998;147:259-268.

40 Broderick J, Brott T, Kothari R, Miller R, Khoury J, Pancioli A, Gebel J, Mills D, Minneci L, Shukla R: The Greater Cincinnati/ Northern Kentucky Stroke Study: preliminary first-ever and total incidence rates of stroke among blacks. Stroke 1998;29:415421.

41 Kissela B, Schneider A, Kleindorfer D, Khoury J, Miller R, Alwell K, Woo D, Szaflarski J, Gebel J, Moomaw C, Pancioli A, Jauch E, Shukla $\mathrm{R}$, Broderick J: Stroke in a biracial population: the excess burden of stroke among blacks. Stroke 2004;35:426-431.

42 Morgenstern LB, Smith MA, Lisabeth LD, Risser JM, Uchino K, Garcia N, Longwell PJ, McFarling DA, Akuwumi O, Al-Wabil A, AlSenani F, Brown DL, Moyé LA: Excess stroke in Mexican Americans compared with nonHispanic Whites: the brain attack surveillance in corpus christi project. Am J Epidemiol 2004; 160:376-383.

43 Sacco RL, Kargman DE, Gu Q, Zamanillo MC: Race-ethnicity and determinants of intracranial atherosclerotic cerebral infarction. The northern Manhattan stroke study. Stroke 1995;26:14-20.

44 Bravata DM, Wells CK, Gulanski B, Kernan WN, Brass LM, Long J, Concato J: Racial disparities in stroke risk factors: the impact of socioeconomic status. Stroke 2005;36:15071511.

45 Sacco RL, Boden-Albala B, Abel G, Lin IF, Elkind M, Hauser WA, Paik MC, Shea S: Raceethnic disparities in the impact of stroke risk factors: the northern Manhattan stroke study. Stroke 2001;32:1725-1731. 
46 Howard G, Lackland DT, Kleindorfer DO, Kissela BM, Moy CS, Judd SE, Safford MM, Cushman M, Glasser SP, Howard VJ: Racial differences in the impact of elevated systolic blood pressure on stroke risk. JAMA Intern Med 2013;173:46-51.

47 Dong C, Rundek T, Wright CB, Anwar Z, Elkind MS, Sacco RL: Ideal cardiovascular health predicts lower risks of myocardial infarction, stroke, and vascular death across whites, blacks, and hispanics: the northern Manhattan study. Circulation 2012;125: 2975-2984.

48 Howard G, Cushman M, Kissela BM, Kleindorfer DO, McClure LA, Safford MM, Rhodes JD, Soliman EZ, Moy CS, Judd SE, Howard VJ: Traditional risk factors as the underlying cause of racial disparities in stroke: lessons from the half-full (empty?) glass. Stroke 2011; 42:3369-3375.

49 Levine DA, Langa KM, Rogers MA: Acute infection contributes to racial disparities in stroke mortality. Neurology 2014;82:914921.

50 Cruz-Flores S, Rabinstein A, Biller J, Elkind MS, Griffith P, Gorelick PB, Howard G, Leira EC, Morgenstern LB, Ovbiagele B, Peterson E, Rosamond W, Trimble B, Valderrama AL: Racial-ethnic disparities in stroke care: the American experience: a statement for healthcare professionals from the American Heart Association/American Stroke Association. Stroke 2011;42:2091-2116.

51 Schwamm LH, Reeves MJ, Pan W, Smith EE, Frankel MR, Olson D, Zhao X, Peterson E, Fonarow GC: Race/ethnicity, quality of care, and outcomes in ischemic stroke. Circulation 2010;121:1492-1501.

52 Lauer MS, Collins FS: Using science to improve the nation's health system: NIH's commitment to comparative effectiveness research. JAMA 2010;303:2182-2183.

53 Walker MF, Fisher RJ, Korner-Bitensky N, McCluskey A, Carey LM: From what we know to what we do: translating stroke rehabilitation research into practice. Int J Stroke 2013; 8:11-17.

54 Flaspohler P, Lesesne CA, Puddy RW, Smith E, Wandersman A: Advances in bridging research and practice: introduction to the second special issue on the interactive system framework for dissemination and implementation. Am J Community Psychol 2012;50: 271-281.

55 Cadilhac DA, Kim J, Lanning NA, Kapral MA, Schwamm LH, Dennis MS, Norrving B, Meretoja A: National stroke registries for monitoring and improving the quality of hospital care: a systematic review. Int J Stroke 2015.

56 Schwamm LH, Fonarow GC, Reeves MJ, Pan W, Frankel MR, Smith EE, Ellrodt G, Cannon CP, Liang L, Peterson E, LaBresh KA: Get with the guidelines-stroke is associated with sustained improvement in care for patients hospitalized with acute stroke or transient ischemic attack. Circulation 2009;119:107115.

57 de Carvalho JJ, Alves MB, Viana GÁ, Machado CB, dos Santos BF, Kanamura AH, Lottenberg CL, Neto MC, Silva GS: Stroke epidemiology, patterns of management, and outcomes in Fortaleza, Brazil: a hospital-based multicenter prospective study. Stroke 2011; 42:3341-3346.

58 Hsieh FI, Lien LM, Chen ST, Bai CH, Sun MC, Tseng HP, Chen YW, Chen CH, Jeng JS, Tsai SY, Lin HJ, Liu CH, Lo YK, Chen HJ, Chiu HC, Lai ML, Lin RT, Sun MH, Yip BS, Chiou HY, Hsu CY: Get with the guidelines-stroke performance indicators: surveillance of stroke care in the Taiwan stroke registry: get with the guidelines-stroke in Taiwan. Circulation 2010;122:1116-1123.

59 Balas EA, Boren SA: Managing clinical knowledge for health care improvement; in Bemmel J, McCray AT (eds): Yearbook of Medical Informatics 2000: Patient-Centered Systems. Stuttgart, Schattauer Verlagsgesellschaft $\mathrm{mbH}, 2000$, pp 65-70.

60 Westfall JM, Mold J, Fagnan L: Practice-based research - 'blue highways' on the NIH roadmap. JAMA 2007;297:403-406.

61 Sung NS, Crowley WF Jr, Genel M, Salber P, Sandy L, Sherwood LM, Johnson SB, Catanese V, Tilson H, Getz K, Larson EL, Scheinberg D, Reece EA, Slavkin H, Dobs A, Grebb J, Martinez RA, Korn A, Rimoin D: Central challenges facing the national clinical research enterprise. JAMA 2003;289:1278-1287.

62 Vickrey BG, Hirtz D, Waddy S, Cheng EM, Johnston SC: Comparative effectiveness and implementation research: directions for neurology. Ann Neurol 2012;71:732-742.

63 Congressional Budget Office: Research on the Comparative Effectiveness of Medical Treatment: Issues and Options for an Expanded Federal Role. Washington, Congressional Budget Office, 2007.

64 Burwell SM: Setting value-based payment goals - HHS efforts to improve U.S. health care. N Engl J Med 2015;372:897-899.

65 Institute of Medicine: Clinical Practice Guidelines We Can Trust. Washington, National Academy of Sciences, 2011.

66 Institute of Medicine: Finding What Works in Health Care: Standards for Systematic Reviews. Washington, National Academy of Sciences, 2011.

67 Birbeck GL, Zingmond DS, Cui X, Vickrey BG: Multispecialty stroke services in California hospitals are associated with reduced mortality. Neurology 2006;66:1527-1532.

68 Vital signs: awareness and treatment of uncontrolled hypertension among adults United States, 2003-2010. MMWR Morb Mortal Wkly Rep 2012;61:703-709.

69 Egan BM, Zhao Y, Axon RN: US trends in prevalence, awareness, treatment, and control of hypertension, 1988-2008. JAMA 2010;303: 2043-2050.

70 Cheng EM, Asch SM, Brook RH, Vassar SD, Jacob EL, Lee ML, Chang DS, Sacco RL, Hsiao AF, Vickrey BG: Suboptimal control of atherosclerotic disease risk factors after cardiac and cerebrovascular procedures. Stroke 2007; 38:929-934.

71 National Institute of Neurological Disorders and Stroke: NIH Awards $\$ 40$ Million in Grants to Reduce Stroke Disparities in the U.S. NIH/NINDS.

72 Feigin VL, Howard G: The importance of epidemiological studies should not be downplayed. Stroke 2008;39:1-2.

73 Feigin V: Neuroepidemiology: a brighter look for the future. Neuroepidemiology 2013;41:1.

74 Sampson UK, Mensah GA, Narula J: Implementation research: an imperative for improving global health and health inequities. Glob Heart 2015;10:1-2.

75 Mensah GA: Embracing dissemination and implementation research in cardiac critical care. Glob Heart 2014;9:363-366. 